\title{
Photocatalytic Degradation of Organic Dyes under Visible Light on $\mathrm{N}$-Doped $\mathrm{TiO}_{2}$ Photocatalysts
}

\author{
Olga Sacco, ${ }^{1}$ Marco Stoller, ${ }^{2}$ Vincenzo Vaiano, ${ }^{1}$ Paolo Ciambelli, ${ }^{1}$ Angelo Chianese, ${ }^{2}$ \\ and Diana Sannino ${ }^{1}$
}

${ }^{1}$ Department of Industrial Engineering, University of Salerno, Via Ponte Don Melillo, Salerno, 84084 Fisciano, Italy
${ }^{2}$ Department of Chemical Engineering, University of Rome "La Sapienza", Via Eudossiana 18, 00184 Rome, Italy

Correspondence should be addressed to Diana Sannino, dsannino@unisa.it

Received 4 August 2012; Revised 5 September 2012; Accepted 12 September 2012

Academic Editor: Jiaguo Yu

Copyright (C) 2012 Olga Sacco et al. This is an open access article distributed under the Creative Commons Attribution License, which permits unrestricted use, distribution, and reproduction in any medium, provided the original work is properly cited.

\begin{abstract}
This study was focused on the application of white and blue light emitting diodes (LEDs) as sources for the photocatalytic degradation of organic dyes in liquid phase with visible light. The photocatalytic activity of $\mathrm{N}$-doped titanium dioxide, synthesized by direct hydrolysis of titanium tetraisopropoxide with ammonia, was evaluated by means of a batch photoreactor. The bandgap energy of titanium dioxide was moved in the visible range from $3.3 \mathrm{eV}$ to $2.5 \mathrm{eV}$. The visible light responsive photocatalysts showed remarkably effective activity in decolorization process and in the removal of total organic carbon. Methylene blue was also used as a model dye to study the influence of several parameters such as catalyst weight and initial concentration. The effect of dye on the photocatalytic performance was verified with methyl orange (MO). The results demonstrated that the right selection of operating conditions allows to effectively degrade different dyes with the $\mathrm{N}$-doped $\mathrm{TiO}_{2}$ photocatalysts irradiated with visible light emitted by LEDs.
\end{abstract}

\section{Introduction}

In recent years, an enormous interest has been devoted to heterogeneous photocatalysis using oxide semiconductors owing to its potential applications to both environmental applications and organic synthesis [1-17]. Titanium dioxide, $\mathrm{TiO}_{2}$, is characterized by chemical stability, no toxicity and cheap production cost, so that it represents one of the most important oxides employed in several fields of photochemistry, for example, in environmental remediation, photoelectrolysis of water and dye-sensitized solar cells [18-22]. Since $\mathrm{TiO}_{2}$ absorbs only a small fraction of the solar spectrum emission, due to the value of its bandgap energy $(3.0-3.3 \mathrm{eV})$, the metal-doped $\mathrm{TiO}_{2}$ has attracted considerable attention due to its reported activity in the visible light. Various metals such as Fe, Cr, Co, Mo, and $\mathrm{V}$ have been employed to tune the electronic structure and enhance the photocatalytic activity of titanium dioxide [2325]. However, metal doping can result in thermal instability and increase of carriers trapping, which may decrease the photocatalytic efficiency. Furthermore, the typical preparation of transition metal-doped $\mathrm{TiO}_{2}$ requires more expensive ion-implantation facilities [26, 27].

Recently, many efforts have been made to modify titanium dioxide with nonmetals, such as $\mathrm{B}, \mathrm{C}, \mathrm{N}, \mathrm{S}$, and $\mathrm{F}$, to efficiently extend the photoresponse from the UV to the visible light region [28-40]. Furthermore, some theoretical calculations have also been performed to suggest that anion doping of $\mathrm{TiO}_{2}$ has considerable effects on the band gap alteration. Since the first report by Kobayakawa et al. [41], considerable research has been done with respect to the preparation, characterization, photocatalytic activity, and mechanism of nitrogen-doped $\mathrm{TiO}_{2}$ in visible light. The $\mathrm{N}$-doped $\mathrm{TiO}_{2}$ seems to be the most promising among the so-called second generation photocatalysts. N-doping can be obtained by various methods such as sputtering [42], treating of $\mathrm{TiO}_{2}$ powders in ammonia atmosphere [43], or hydrolysis with urea in the presence of organic or inorganic titanium-based compounds [44]. N-doped titanium dioxide nanoparticles $\left(\mathrm{N}-\mathrm{TiO}_{2}\right)$ demonstrated the 
ability to degradate using tungsten bulb lamp [45] also industrial wastewaters as tannery wastewater, which instead requires a complex combination of conventional treatments to be satisfactory depolluted, as reported in [46].

Until now, there are very few reports on the use of LEDs emitting in visible region for the degradation of methylene blue, typically performed at very low dye concentration $(\leq 1 \mathrm{ppm})$ [47].

For the above reasons the objective of this study was to explore the possibility of using this type of LEDs as source of visible light for the photocatalytic degradation of dyes with higher concentration in the presence of $\mathrm{N}$ doped $\mathrm{TiO}_{2}$ photocatalyst. The catalyst was obtained by direct nitration with $\mathrm{NH}_{3}$ during the hydrolysis of titanium tetraisopropoxide. The influence of several parameters, such as catalyst weight, methylene blue concentration, and dye type were investigated.

\section{Experimental}

2.1. Photocatalysts Preparation and Characterization. Ndoped $\mathrm{TiO}_{2}$ photocatalysts were prepared by sol-gel method, according to the modified synthetic procedure developed by Sato [47]. Different amounts $(25 \mathrm{~mL}, 50 \mathrm{~mL}, 75 \mathrm{~mL}$, and $100 \mathrm{~mL}$ ) of ammonia aqueous solution at $30 \mathrm{wt} \%$, supplied by Carlo Erba, were added quickly to $25 \mathrm{~mL}$ of $97 \mathrm{wt} \%$ titanium tetraisopropoxide (TTIP by Sigma Aldrich) at $0^{\circ} \mathrm{C}$, while the solution was vigorously stirred, leading to the formation of a white precipitate. The precipitate was carefully washed with water and centrifuged to be separated. Finally, the obtained powder was dried and calcined at $450^{\circ} \mathrm{C}$ for 30 minutes to get $\mathrm{TiO}_{2}$ in the anatase phase. X-ray diffraction (XRD) measurements of the obtained yellow samples were carried out with an X-ray microdiffractometer Rigaku Dmax-RAPID, with $\mathrm{Cu}-\mathrm{K} \alpha$ radiation. Laser Raman spectra were obtained at room temperature with a Dispersive MicroRaman (Invia, Renishaw), equipped with $785 \mathrm{~nm}$ diodelaser, in the range $100-2500 \mathrm{~cm}^{-1}$ Raman shift. Aggregates sizes of photocatalyst particles in aqueous suspension were measured by a DLS instrument (Brookhaven Plus 91). UV-Vis DRS measurements were obtained by means of a Perkin Elmer spectrometer Lambda 35 using a RSA-PE-20 reflectance spectroscopy accessory (Labsphere Inc., North Sutton, NH). All spectra were obtained using an $8^{\circ}$ sample positioning holder, giving total reflectance relative to a calibrated standard SRS-010-99 (Labsphere Inc., North Sutton, $\mathrm{NH})$. The reflectance data were reported as the $F\left(R_{\infty}\right)$ value from Kubelka-Munk theory versus the wavelength. Band gap determinations were made by plotting $\left[F\left(R_{\infty}\right) * h \nu\right]^{2}$ versus $h \nu(\mathrm{eV})$ and calculating the $x$ intercept of a line passing through $0.5<F\left(R_{\infty}\right)<0.8$.

2.2. Photocatalytic Activity Tests under Visible Light. In a typical activity test a defined amount of photocatalyst was suspended in $100 \mathrm{~mL}$ of $\mathrm{MB}$ solution. The suspension was left in dark condition for 2 hours to reach the adsorption equilibrium, and then photocatalytic reaction was initiated under visible light up to $3 \mathrm{~h}$. The experiments were

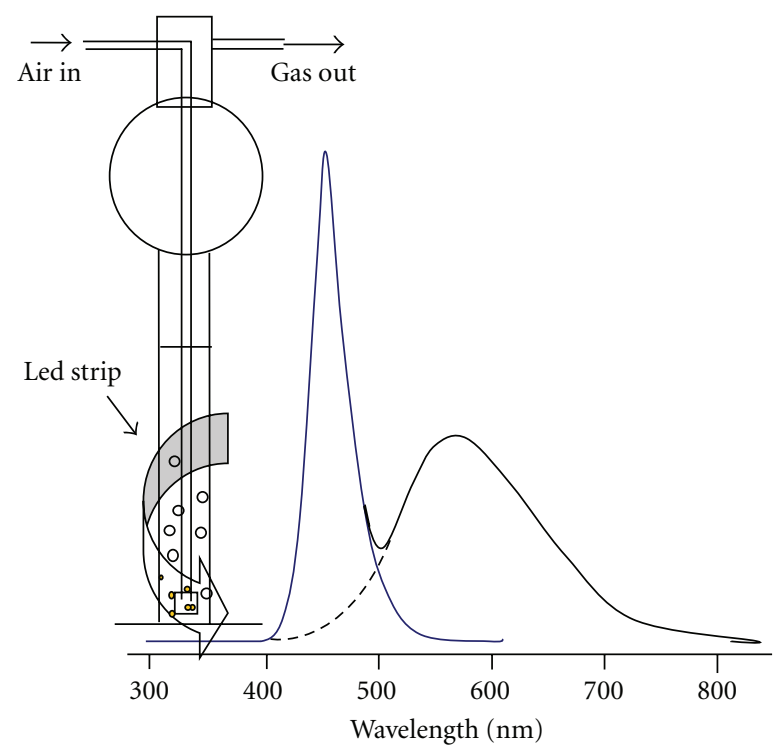

Figure 1: Emission spectrum of the light sources and schematic picture of the photoreactor.

performed with a pyrex cylindrical photoreactor (ID = $2.5 \mathrm{~cm})$ equipped with an air distributor device $\left(Q_{\text {air }}=\right.$ $150 \mathrm{~cm}^{3} / \mathrm{min}$ (STP)), a magnetic stirrer to maintain the photocatalyst suspended in the aqueous solution, and a temperature controller. The photoreactor was irradiated by a strip composed by 30 white light LEDs (nominal power: $6 \mathrm{~W}$ ) with wavelength emission in the range $400-800 \mathrm{~nm}$ or by a similar number of blue light LEDs (nominal power: $6 \mathrm{~W}$ ) with wavelength emission in the range $400-550 \mathrm{~nm}$. The LEDs strip was positioned around the reactor so that the light source uniformly illuminated the reaction volume. The curve inside Figure 1 represents the emission spectrum of white LEDs, while the fraction of curve coloured in blue evidence the spectrum emission of blue LEDs. On the left side of the same figure a schematic picture of the photocatalytic reactor is presented. Slurry samples were collected at fixed time intervals, and centrifuged for 20 minutes at $4000 \mathrm{rpm}$ for removing photocatalyst particles. The centrifuged samples were analysed to determine the change of dyes concentration, measured with a Perkin Elmer UV-Vis spectrophotometer at $\lambda=663 \mathrm{~nm}$. A standard calibration curve was obtained for different $\mathrm{MB}$ concentration and allowed to convert absorbance to concentration ( $\mathrm{mg} / \mathrm{L}$ ) units. Total organic carbon (TOC) of solution was evaluated from $\mathrm{CO}_{2}$ obtained by catalytic combustion at $T=680^{\circ} \mathrm{C}$. $\mathrm{CO}_{2}$ produced in gasphase was monitored by continuous analyzers, measuring $\mathrm{CO}, \mathrm{CO}_{2}$ (Uras 14, $\mathrm{ABB}$ ), and $\mathrm{O}_{2}$ (Magnos 106, $\mathrm{ABB}$ ) gaseous concentrations.

\section{Results and Discussion}

The list of catalysts and their bandgap energy is reported in Table 1.

The reflectance measurements of $\mathrm{N}$-doped $\mathrm{TiO}_{2}$ showed that the absorption onset shifted from 380 to $480 \mathrm{~nm}$ 
TABLE 1: List of catalysts and their bandgap.

\begin{tabular}{|c|c|c|c|c|c|c|c|}
\hline Catalysts & $\begin{array}{l}\text { TTIP volume } \\
(\mathrm{mL})\end{array}$ & $\begin{array}{l}\mathrm{NH}_{3} \text { solution } \\
\text { volume }(\mathrm{mL})\end{array}$ & N/Ti molar ratio & $\begin{array}{l}\text { Crystallites } \\
\operatorname{size}^{2}(\mathrm{~nm})\end{array}$ & $\operatorname{SSA}^{3}\left(\mathrm{~m}^{2} / \mathrm{g}\right)$ & $\begin{array}{l}\text { Aggregates } \\
\operatorname{size}^{4}(\mathrm{~nm})\end{array}$ & $\begin{array}{c}\text { Bandgap } \\
\text { energy }^{5}(\mathrm{eV})\end{array}$ \\
\hline $\mathrm{TiO}_{2}{ }^{1}$ & 25 & 0 & - & 7 & 171 & 267 & 3.3 \\
\hline N_1 & 25 & 25 & 4.6 & 16 & 75 & 163 & 2.6 \\
\hline N_2 & 25 & 50 & 9.3 & 15 & 80 & 364 & 2.6 \\
\hline N_3 & 25 & 75 & 13.9 & 16 & 75 & 167 & 2.5 \\
\hline N_4 & 25 & 100 & 18.6 & 15 & 80 & 367 & 2.5 \\
\hline
\end{tabular}

${ }^{1} \mathrm{TiO}_{2}$ by sol-gel method.

${ }^{2}$ From XRD analysis.

${ }^{3}$ From the equation SSA $=6000 *(\rho * d)^{-1}$, where SSA is the calculated specific surface area, $d$ is crystallites size $(\mathrm{nm})$ and $\rho$ is $\mathrm{TiO}_{2}$ density $\left(\mathrm{g} / \mathrm{cm}^{3}\right)$, based on the assumption of spherical and nonporous particles [48].

${ }^{4}$ From DLS instrument.

${ }^{5}$ From UV-Vis spectra.

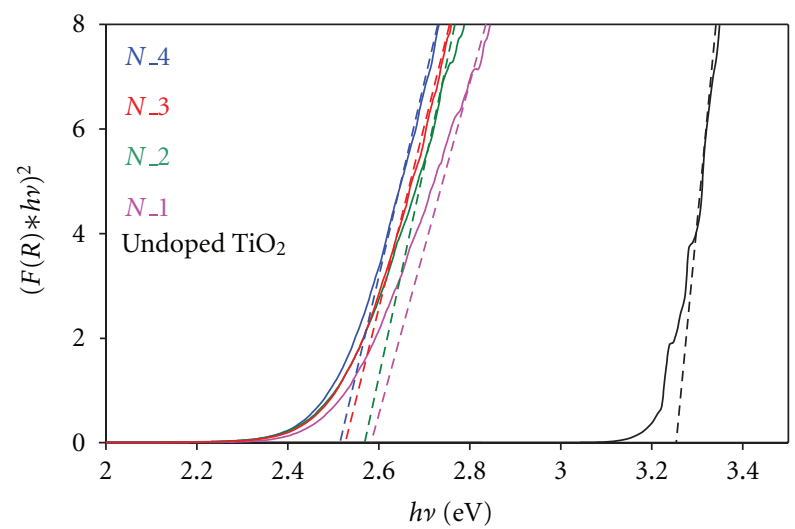

FIGURe 2: Bandgap estimation from UV-Vis DRS.

determining a decrease of bandgap values from $3.3 \mathrm{eV}$ (the typical bandgap of undoped $\mathrm{TiO}_{2}$ ) to $2.5 \mathrm{eV}$ (Figure 2), which is an unexpected value for the only anatase phase. This change in bandgap is therefore attributed to the presence of nitrogen in the crystal structure phase. This result confirms the ability of photocatalysts to absorb visible light.

XRD analysis (not reported) revealed that for undoped $\mathrm{TiO}_{2}$ and for $\mathrm{N}-\mathrm{TiO}_{2}$ samples the only crystalline phase is anatase and it did not change after the doping process. The average size of $\mathrm{TiO}_{2}$ crystallites was calculated using the Scherrer equation [49] on diffraction plane (101) and the obtained values are reported in Table 1 . The crystallite average size was $16 \mathrm{~nm}$ for $\mathrm{N}_{-} 1$ and $\mathrm{N}_{-} 3$ samples, while for N_2 and N_4 it was $15 \mathrm{~nm}$. In contrast, DLS overestimated the size of $\mathrm{TiO}_{2}$ particles due to agglomeration in the suspension. For $\mathrm{N}-\mathrm{TiO}_{2}$ samples, the degree of aggregation increased with decrease in crystallites size due to the high surface energy of smaller particles.

The results obtained from XRD are confirmed by Raman spectra (Figure 3), since the band positions are in complete accordance with those reported in previous studies for anatase powder [50-61]. In fact the Raman modes at 141, $194,394,515$, and $636 \mathrm{~cm}^{-1}$ are assigned to the anatase phase.

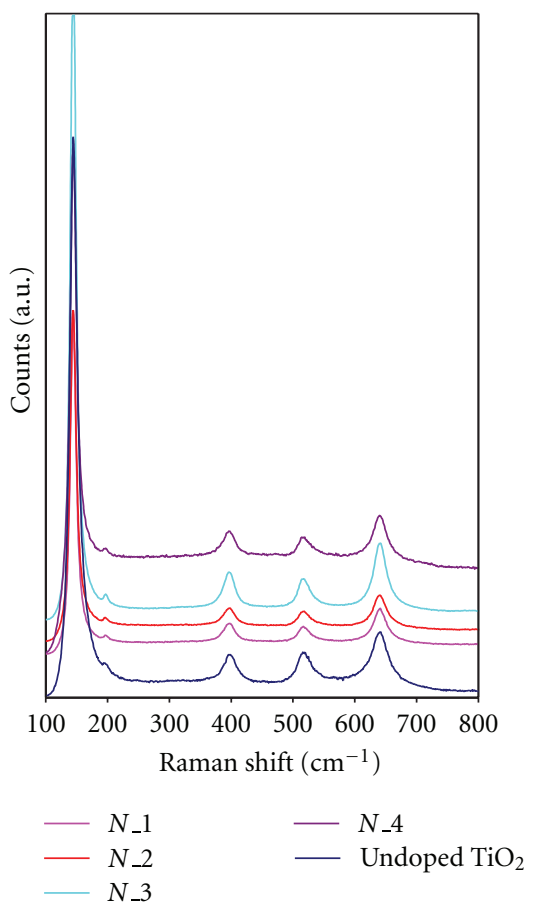

Figure 3: Raman spectra of undoped $\mathrm{TiO}_{2}, \mathrm{~N}_{-} 1 ; \mathrm{N}_{-} .2$; N_3; N_4.

The behaviour of MB decolourisation under visible light generated by white LEDs is represented in (Figure 4) for undoped $\mathrm{TiO}_{2}$ and doped $\mathrm{TiO}_{2}$ with different nitrogen content.

In dark conditions a decrease of $\mathrm{MB}$ concentration was observed during the first hour of the test and it was unchanged in the second hour, indicating that the adsorption equilibrium of dye on catalyst surface was reached. The curves show that $\mathrm{N}-\mathrm{TiO}_{2}$ catalysts have different amounts of MB adsorbed in dark. To explain this last result, the specific area was estimated (Table 1); for the sample $\mathrm{N}_{-} 1$ and N_3 it was $75 \mathrm{~m}^{2} / \mathrm{g}$, while for N_2 and N_4 it was $80 \mathrm{~m}^{2} / \mathrm{g}$. As expected, the amount of organic dye adsorbed increases the higher is the specific surface area, fairly accordingly to the differences in the area values, as shown in Figure 4. 


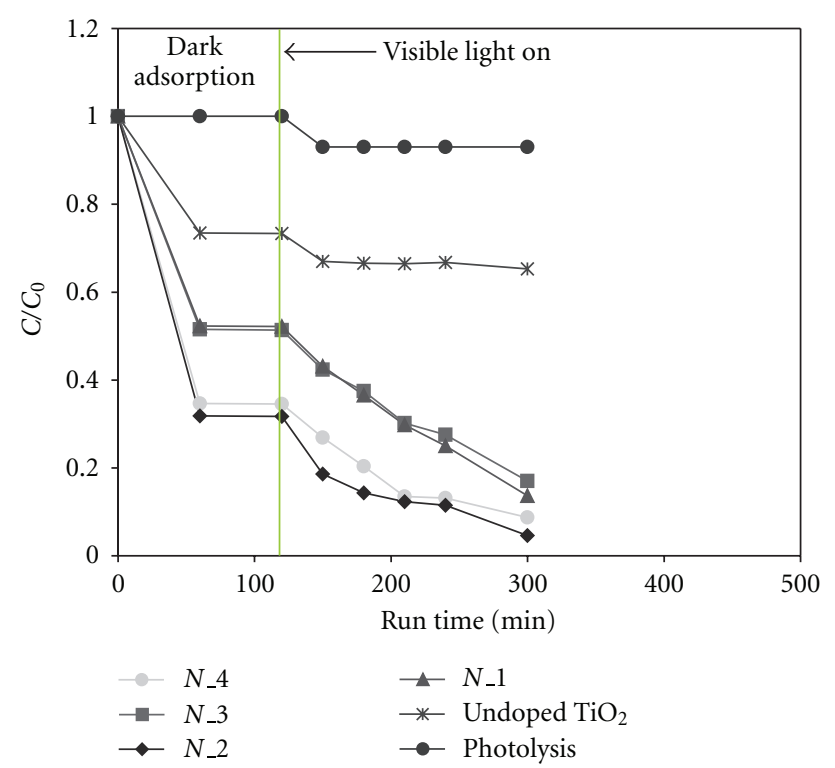

FIgURE 4: Decolorization of MB under visible light generated by white LEDs; catalyst weight: $0.3 \mathrm{~g}$; initial $\mathrm{MB}$ concentration: $7.5 \mathrm{ppm}$.

After the dark period, the solution was irradiated with visible light and the reaction started to occur. Figure 4 shows that undoped $\mathrm{TiO}_{2}$ is slightly effective for $\mathrm{MB}$ decolourization, the $C / C_{0}$ reduction being about $8 \%$, a value similar to that of photolysis reaction $(7 \%)$. On the contrary, all the $\mathrm{N}$-doped $\mathrm{TiO}_{2}$ photocatalysts exhibited higher photocatalytic activity under visible light irradiation. The order of decolorization activity of $\mathrm{N}$-doped $\mathrm{TiO}_{2}$ after 180 min was as following: N_2 $>$ N_4 $>$ N_3 N_1. The final value of $\mathrm{MB}$ conversion depends on dye concentration after the dark period.

The decolourization of $\mathrm{MB}$ does not necessary correspond to the oxidation and mineralization of the molecule; in fact the reduced form of $\mathrm{MB}$ (LMB, leuco) which is colourless can be produced in the presence of light [49]. The lack of coincidence among the best performing samples with respect to either decolorization or mineralization can be the result of different routes followed by $\mathrm{MB}$ during irradiation. Consider the following:

$$
\begin{gathered}
\mathrm{h}^{+}+\mathrm{OH}^{-} \longrightarrow \mathrm{OH}^{\bullet} \\
\mathrm{MB}+\mathrm{OH}^{\bullet} \longrightarrow \text { INTERMEDIATES } \longrightarrow \mathrm{CO}_{2} \\
\mathrm{MB}+\mathrm{e}^{-} \longrightarrow \mathrm{MB}^{\bullet-} \\
2 \mathrm{MB}^{\bullet^{-}} \longrightarrow \mathrm{MB}+\mathrm{LMB} \\
\mathrm{LMB}+\mathrm{OH}^{\bullet} \longrightarrow \text { INTERMEDIATES } \longrightarrow \mathrm{CO}_{2}
\end{gathered}
$$

The MB molecule can be transformed into LMB through reduction by electrons in the conduction band (4) or oxidized by interactions with the valence band holes or native $\mathrm{OH}$ species, starting with a de-methylation step to be finally mineralized (2). For long reaction times also LMB can be further degradated and mineralized.

The analysis of gases coming from the photoreactor showed the presence of $\mathrm{CO}_{2}$ and $\mathrm{SO}_{2}$ during the visible light irradiation, confirming the occurrence of $\mathrm{MB}$ mineralization (Figure 5). In fact, a significant TOC reduction was obtained. Its final value increased up to $97 \%$ by increasing the doping level (Figure 6). In this case, the order of activity was: N_4 > N_3 $>$ N_2 $\gg$ N_1.

The photocatalyzed decolorization process can be described by a first-order kinetic equation (6) with respect to the concentration of $\mathrm{MB}[62,63]$. Consider

$$
-\ln \frac{C}{C_{0}^{*}}=k_{i} \cdot t,
$$

where:

$C=$ concentration of $\mathrm{MB}$ at any given time;

$C_{0}^{*}=$ concentration of $\mathrm{MB}$ after dark adsorption:

$t=$ irradiation time;

$k_{i}=$ apparent kinetic constant.

The obtained results are plotted in Figure 7.

The order of kinetic constants of $\mathrm{N}$-doped $\mathrm{TiO}_{2}$ after $150 \mathrm{~min}$ of light irradiation is $k_{2}>k_{4}>k_{3} \sim k_{1}$.

Many reports suggest that the amount of catalyst plays a major role in the degradation of organic compounds or dyes in photocatalytic systems. To avoid the use of a catalyst excess, it is necessary to identify the optimum loading for an efficient removal of dye or organic compound. So it is necessary to optimize the amount of catalyst with respect to the highest photocatalytic activity.

To study the effect of the amount of catalysts, different quantities of powder between 0.05 and $1.5 \mathrm{~g}$ were used. The initial concentration of $\mathrm{MB}$ dye $(7.5 \mathrm{ppm})$ was kept the same in all these experiments. Figure 8 shows the effect of the amount of catalyst on the conversion of $\mathrm{MB}$ in the presence of white LEDs. The progress of the conversion is linear up to $0.3 \mathrm{~g}$, while for further increase of catalyst amount, the conversion stabilizes. These data indicate that $0.3 \mathrm{~g}$ of powders are completely exposed to the radiation. This phenomenon may be explained considering that with an increase of catalyst loading in the aqueous medium, the light penetration through the solution becomes difficult. Therefore $0.3 \mathrm{~g}$ of photocatalyst loading is considered to be an optimal value.

Also the dye concentration plays a key role in the photocatalytic degradation. The effect of MB initial concentration on the photocatalytic activity was checked in the range between 4 and 95 ppm with N_4 catalyst and optimal catalyst loading ( $0.3 \mathrm{~g}$ in $100 \mathrm{~mL}$ of solution). The trend of the curves was similar and it is shown in Figure 9. After 120 minutes of dark adsorption, the photocatalytic test started. At fixed reaction times, the increase of $\mathrm{MB}$ initial concentration determined a decrease of the photocatalytic activity. This could be due to the increase of colour intensity of the solution that reduces the light penetration into the aqueous medium, meaning that the path length of photons inside the solution decreases. After 180 minutes of irradiation the final value of the decolorization was $100 \%$ in the case of $4 \mathrm{ppm}$ and $15 \%$ in the case of $95 \mathrm{ppm} \mathrm{MB}$ initial concentration. 


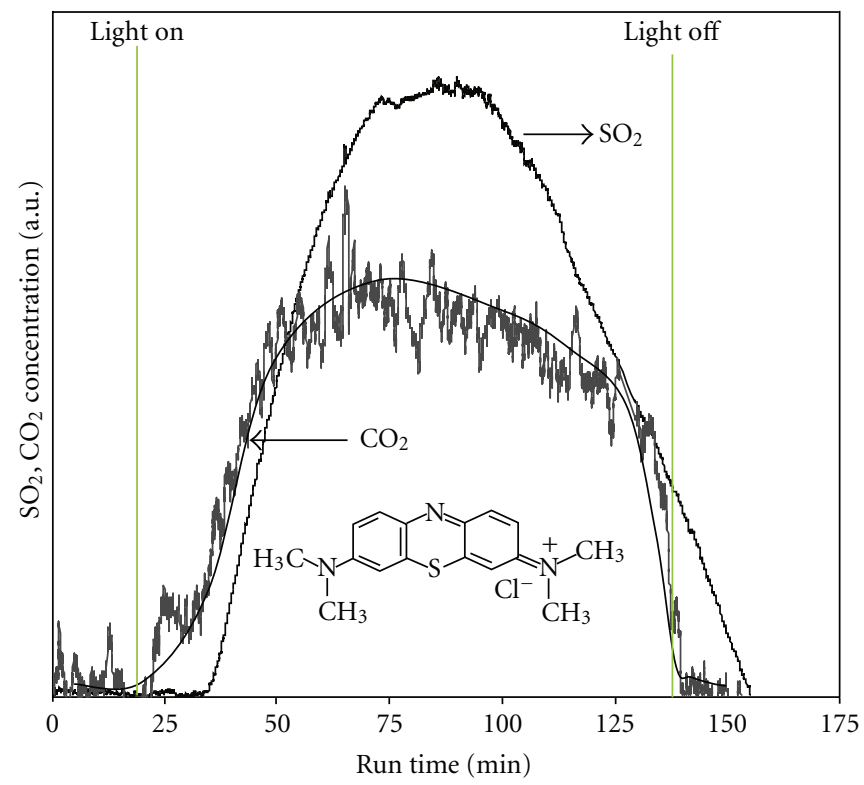

FIGURE 5: Gas analysis phase during visible irradiation of MB solution.

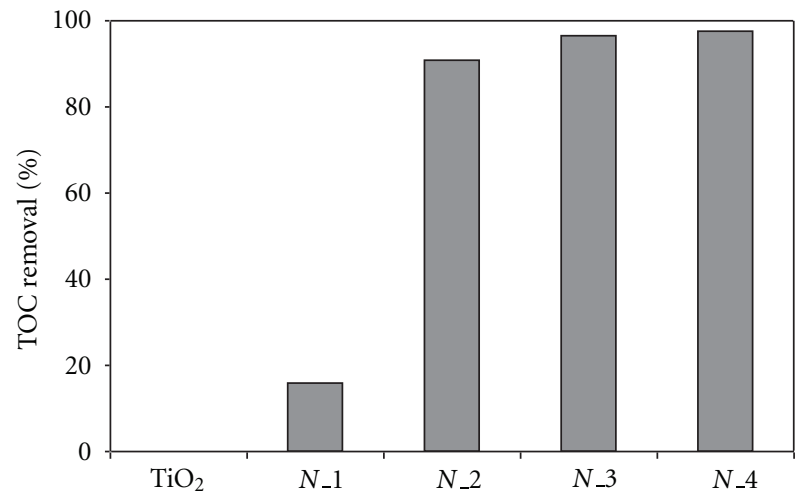

Figure 6: TOC removal after $180 \mathrm{~min}$ of irradiation time; catalyst weight: $0.3 \mathrm{~g}$; initial $\mathrm{MB}$ concentration: $7.5 \mathrm{ppm}$.

The same effect was observed by Matthews during the photocatalytic degradation of $\mathrm{MB}$ with $\mathrm{TiO}_{2}$ catalysts [48].

Moreover, the efficiency of the system was also evaluated with blue LEDs as source of visible light and methyl orange (MO) as organic dye. Figure 10 shows the comparison between the obtained results in presence of white and blue LEDs. As expected from the evaluation of N_4 bandgap energy $(2.5 \mathrm{eV})$, only a fraction of radiation is used in the decolorization process. In fact, the curves related to the $\mathrm{MB}$ concentration during the irradiation time showed a similar trend because the range of radiation used by the photocatalyst was that one having an emission wavelength lower than $440 \mathrm{~nm}$. Similar results were obtained for methyl orange (MO).

The photocatalytic stability of $\mathrm{N}$-doped $\mathrm{TiO}_{2}$ was evaluated with recycling experiments (Figure 11). In the first cycle, the amount of $\mathrm{MB}$ adsorbed was lower than that

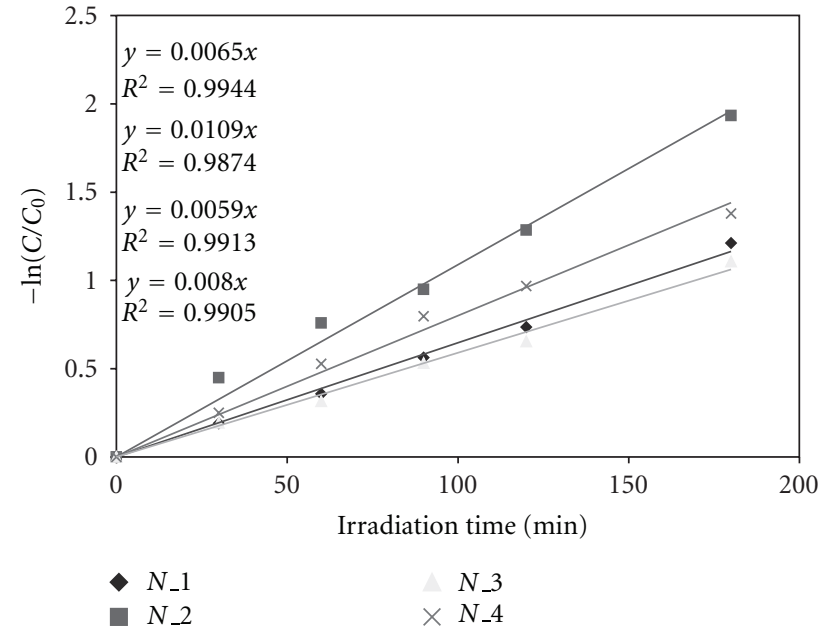

FIGURE 7: Evaluation of decolorization kinetic.

one obtained with fresh catalyst because, using the same catalyst coming from the first test, a certain quantity of dye is already adsorbed. The rate of dye removal depends on the initial concentration in solution, so it is higher, the higher is residual $\mathrm{MB}$ after dark adsorption. However, it must be noted that the photocatalytic activity remained high and the level of final MB removal was the same at the end of the test, indicating that no deactivation occurred and the dye concentration decreased continuously under visible light irradiation.

\section{Conclusions}

In this study, the evaluation of the photodegradation of methylene blue (MB), as dye model system, in presence of 


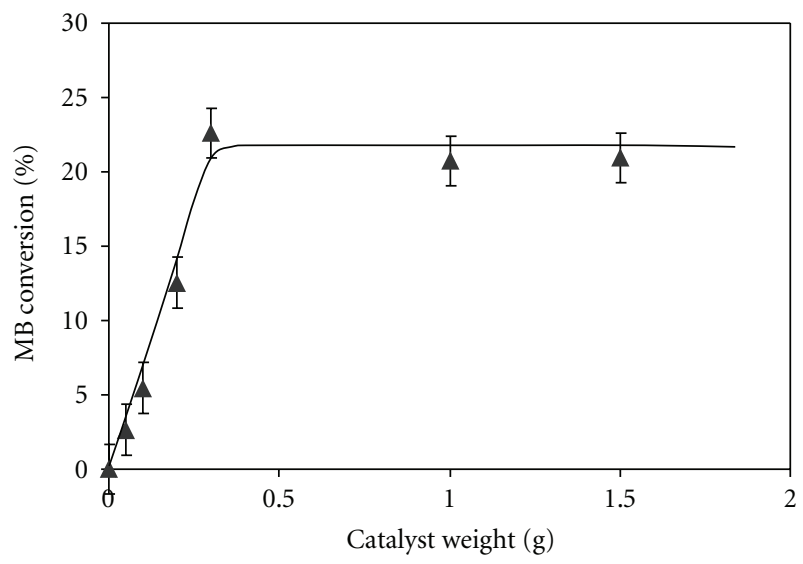

Figure 8: Evaluation of decolorization after 30 minute with different amount of N_4 catalyst.

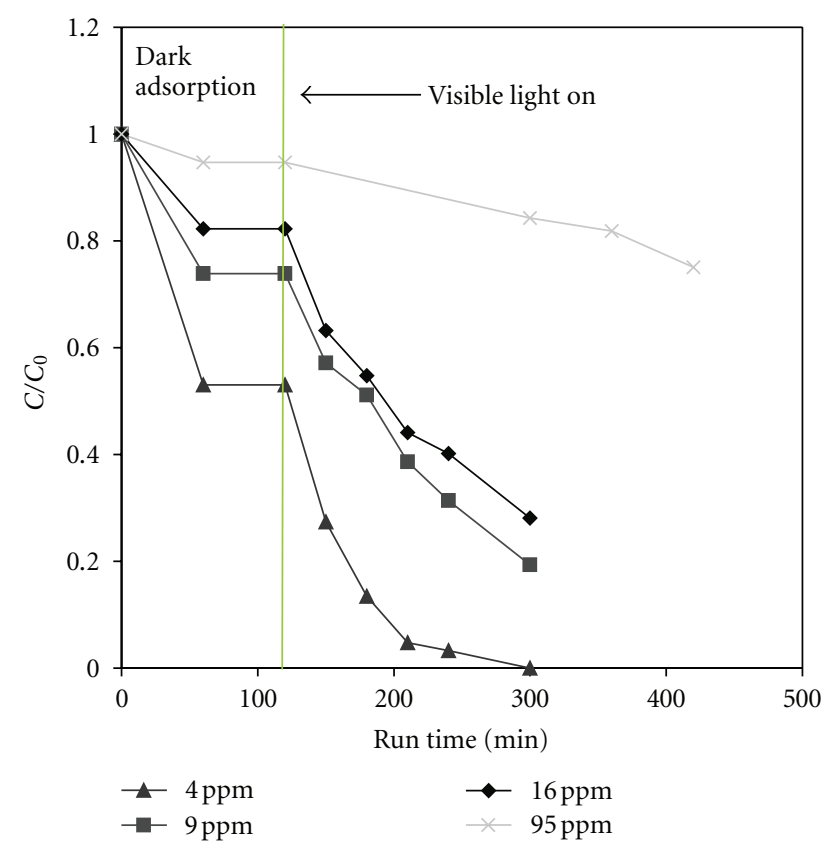

Figure 9: Evaluation of decolorization with different initial concentration of MB; catalyst: N_4.

white and blue light emitting diodes (LEDs) as source of visible light, was evaluated. The photoreactivity was assessed over N-doped $\mathrm{TiO}_{2}$ photocatalysts in batch experiments, evaluating the abatement of methylene blue, and in addition of methyl orange. The best catalyst was $\mathrm{N} \_4$ that showed remarkable efficiencies in decolorization process and in the removal of total organic carbon. The influence of several parameters such as catalyst weight, dye concentration and type, light source was assessed.

\section{References}

[1] P. Ciambelli, D. Sannino, V. Palma, V. Vaiano, and R. S. Mazzei, "Intensification of gas-phase photoxidative dehydrogenation of ethanol to acetaldehyde by using phosphors as light

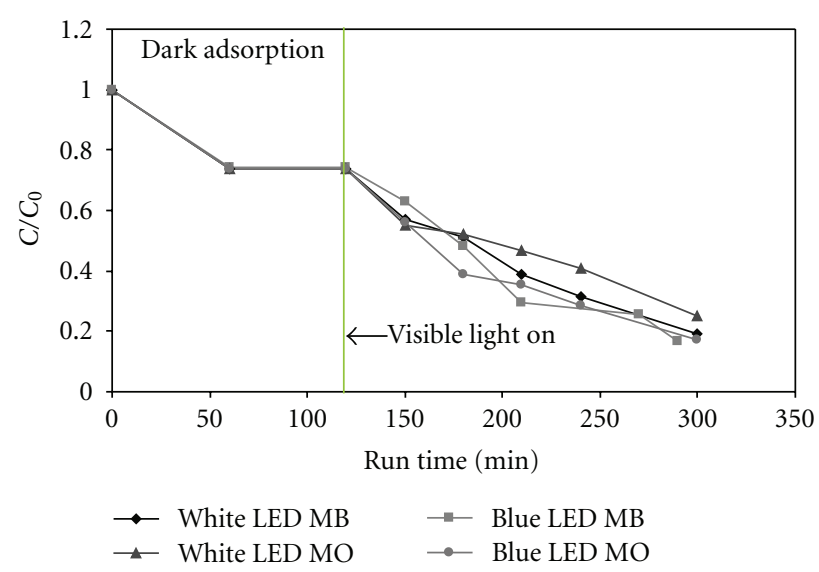

FIGURE 10: Evaluation of decolorization with different dyes and different light source; initial MB and MO concentration: 9 ppm.

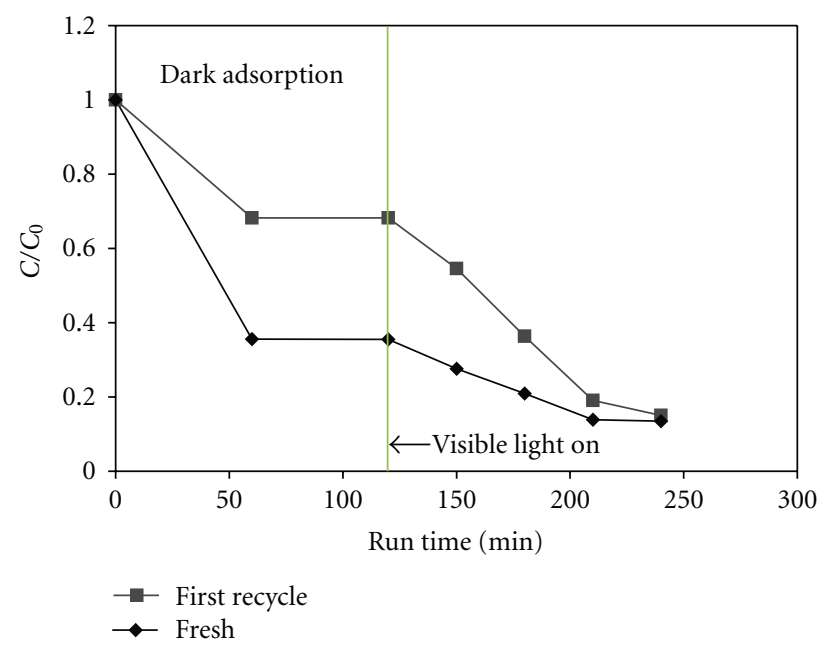

FIGURE 11: Evaluation of decolorization performances obtained on $\mathrm{N} \_4$ photocatalyst after one recycling experiment; initial MB concentration: $7.5 \mathrm{ppm}$.

carriers," Photochemical and Photobiological Sciences, vol. 10, no. 3, pp. 414-418, 2009.

[2] P. Ciambelli, D. Sannino, V. Palma, V. Vaiano, and R. S. Mazzei, "A step forwards in ethanol selective photo-oxidation," Photochemical and Photobiological Sciences, vol. 8, no. 5, pp. 699704, 2009.

[3] P. Ciambelli, D. Sannino, V. Palma, and V. Vaiano, "Photocatalysed selective oxidation of cyclohexane to benzene on $\mathrm{MoO}_{x} / \mathrm{TiO}_{2}$," Catalysis Today, vol. 99, no. 1-2, pp. 143-149, 2005.

[4] P. Ciambelli, D. Sannino, V. Palma, and V. Vaiano, "Cyclohexane photocatalytic oxidative dehydrogenation to benzene on sulphated titania supported $\mathrm{MoO}_{\mathrm{x}}$," Studies in Surface Science and Catalysis, vol. 155, pp. 179-187, 2005.

[5] P. Ciambelli, D. Sannino, V. Palma, V. Vaiano, and R. I. Bickley, "Reaction mechanism of cyclohexane selective photooxidation to benzene on molybdena/titania catalysts," Applied Catalysis, vol. 349, no. 1-2, pp. 140-147, 2008.

[6] P. Ciambelli, V. Palma, D. Sannino, S. Vaccaro, and V. Vaiano, "Selective oxidation of cyclohexane to benzene on 
molybdena-titania catalysts in fluidized bed photocatalytic reactor," Studies in Surface Science and Catalysis, vol. 172, p. 453, 2007.

[7] P. Ciambelli, D. Sannino, V. Palma et al., "Tuning the selectivity of $\mathrm{MoO}_{x}$ supported catalysts for cyclohexane photo oxidehydrogenation," Catalysis Today, vol. 128, no. 3-4, pp. 251-257, 2007.

[8] P. Ciambelli, D. Sannino, V. Palma et al., "Photocatalytic cyclohexane oxidehydrogenation on sulphated $\mathrm{MoO}_{x} / \gamma-\mathrm{Al}_{2} \mathrm{O}_{3}$ catalysts," Catalysis Today, vol. 141, no. 3-4, pp. 367-373, 2009.

[9] J. J. Murcia, M. C. Hidalgo, J. A. Navío, V. Vaiano, P. Ciambelli, and D. Sannino, "Photocatalytic ethanol oxidative dehydrogenation over $\mathrm{Pt} / \mathrm{TiO}_{2}$ : effect of the addition of blue phosphors," International Journal of Photoenergy, vol. 2012, Article ID 687262, 9 pages, 2012.

[10] D. Sannino, V. Vaiano, P. Ciambelli, and L. A. Isupova, "Structured catalysts for photo-fenton oxidation of acetic acid," Catalysis Today, vol. 161, pp. 255-259, 2011.

[11] D. Sannino, V. Vaiano, L. A. Isupova, and P. Ciambelli, "Heterogeneous photo-fenton oxidation of organic pollutants on structured catalysts," Journal of Advanced Oxidation Technologies, vol. 15, no. 2, pp. 294-300, 2012.

[12] D. Sannino, V. Vaiano, L. A. Isupova, and P. Ciambelli, "Photofenton oxidation of acetic acid on supported $\mathrm{LaFeO}_{3}$ and $\mathrm{Pt} / \mathrm{LaFeO}_{3}$ perovskites," Chemical Engineering Transactions, vol. 25, pp. 1013-1018, 2011.

[13] D. Sannino, V. Vaiano, P. Ciambelli, M. C. Hidalgo, J. J. Murcia, and J. A. Navío, "Oxidative dehydrogenation of ethanol over $\mathrm{Au} / \mathrm{TiO}_{2}$ photocatalysts," Journal of Advanced Oxidation Technologies, vol. 15, no. 2, pp. 284-293, 2012.

[14] J. J. Murcia, M. C. Hidalgo, J. A. Navío, V. Vaiano, P. Ciambelli, and P. D. Sannino, "Ethanol partial photoxidation on $\mathrm{Pt} / \mathrm{TiO}_{2}$ catalysts as green route for acetaldehyde synthesis," Catalysis Today, In press.

[15] D. Sannino, V. Vaiano, and P. Ciambelli, "Innovative structured $\mathrm{VO}_{x} / \mathrm{TiO}_{2}$ photocatalysts supported on phosphors for the selective photocatalytic oxidation of ethanol to acetaldehyde," Catalysis Today, In press.

[16] D. Sannino, V. Vaiano, P. Ciambelli, P. Eloy, and E. M. Gaigneaux, "Avoiding the deactivation of sulphated $\mathrm{MoO}_{x} / \mathrm{TiO}_{2}$ catalysts in the photocatalytic cyclohexane oxidative dehydrogenation by a fluidized bed photoreactor," Applied Catalysis A: General, vol. 394, pp. 71-78, 2011.

[17] V. Palma, D. Sannino, V. Vaiano, and P. Ciambelli, "Fluidizedbed reactor for the intensification of gas-phase photocatalytic oxidative dehydrogenation of cyclohexane," Industrial \& Engineering Chemistry Research, vol. 49, no. 21, pp. 10279-10286, 2010.

[18] M. Anpo, "Preparation, characterization, and reactivities of highly functional titanium oxide-based photocatalysts able to operate under UV-visible light irradiation: approaches in realizing high efficiency in the use of visible light," Bulletin of the Chemical Society of Japan, vol. 77, no. 8, pp. 1427-1442, 2004.

[19] G. Cappelletti, S. Ardizzone, C. L. Bianchi et al., "Photodegradation of pollutants in air: enhanced properties of nano- $\mathrm{TiO}_{2}$ prepared by ultrasound," Nanoscale Research Letters, vol. 4, no. 2, pp. 97-105, 2009.

[20] M. Grätzel, "Photoelectrochemical cells," Nature, vol. 414, p. $338,2001$.

[21] X. Chen and S. S. Mao, "Titanium dioxide nanomaterials: synthesis, properties, modifications and applications," Chemical Reviews, vol. 107, no. 7, pp. 2891-2959, 2007.
[22] M. R. Hoffmann, S. T. Martin, W. Choi, and D. Bahnemann, "Environmental applications of semiconductor photocatalysis," Chemical Reviews, vol. 95, pp. 69-96, 1995.

[23] J. Peral, X. Domenech, and D. F. Ollis, "Heterogeneous photocatalysis for purification, decontamination and deodorization of air," Journal of Chemical Technology and Biotechnology, vol. 70, no. 2, pp. 117-140, 1997.

[24] J. Zhao and X. Yang, "Photocatalytic oxidation for indoor air purification: a literature review," Building and Environment, vol. 38, no. 5, pp. 645-654, 2003.

[25] X. Z. Fu, W. A. Zeltner, and M. A. Andreson, "The gas-phase photocatalytic mineralization of benzene on porous titaniabased catalysts," Applied Catalysis B, vol. 6, no. 3, pp. 209-290, 1995.

[26] H. Choi, Y. J. Kim, R. S. Varma, and D. D. Dionysiou, "Thermally stable nanocrystalline $\mathrm{TiO}_{2}$ photocatalysts synthesized via sol-gel methods modified with ionic liquid and surfactant molecules," Chemistry of Materials, vol. 18, no. 22, pp. 53775384, 2006.

[27] B. Li, X. Wang, M. Yan, and L. Li, "Preparation and characterization of nano- $\mathrm{TiO}_{2}$ powder," Materials Chemistry and Physics, vol. 78, no. 1, pp. 184-188, 2003.

[28] A. Fujishima, T. N. Rao, and D. A. Tryk, "Titanium dioxide photocatalysis," Journal of Photochemistry and Photobiology C, vol. 1, no. 1, pp. 1-21, 2000.

[29] A. L. Linsebigler, G. Lu, and J. T. Yates, "Photocatalysis on $\mathrm{TiO}_{2}$ surfaces: principles, mechanisms, and selected results," Chemical Reviews, vol. 95, no. 3, pp. 735-758, 1995.

[30] H. Tada, M. Yamamoto, and S. Ito, "Promoting effect of $\mathrm{MgO}_{x}$ submonolayer coverage of $\mathrm{TiO}_{2}$ on the photoinduced oxidation of anionic surfactants," Langmuir, vol. 15, no. 11, pp. 3699-3702, 1999.

[31] G. Shang, H. Fu, S. Yang, and T. Xu, "Mechanistic study of visible-light-induced photodegradation of 4-chlorophenol by $\mathrm{TiO}_{2-x} \mathrm{~N}_{x}$ with low nitrogen concentration," International Journal of Photoenergy, vol. 2012, Article ID 759306, 9 pages, 2012.

[32] S. Li, S. Lin, J. Liao, N. Pan, D. Li, and J. Li, "Nitrogen-doped $\mathrm{TiO}_{2}$ nanotube arrays with enhanced photoelectrochemical property," International Journal of Photoenergy, vol. 2012, Article ID 794207, 7 pages, 2012.

[33] Q. Xiang, J. Yu, W. Wang, and M. Jaroniec, "Nitrogen self-doped nanosized $\mathrm{TiO}_{2}$ sheets with exposed 001 facets for enhanced visible-light photocatalytic activity," Chemical Communications, vol. 47, no. 24, pp. 6906-6908, 2011.

[34] K. Li, H. Wang, C. Pan, J. Wei, R. Xiong, and J. Shi, "Enhanced photoactivity of $\mathrm{Fe}+\mathrm{N}$ codoped anatase-rutile $\mathrm{TiO}_{2}$ vanowire film under visible light irradiation," International Journal of Photoenergy, vol. 2012, Article ID 398508, 8 pages, 2012.

[35] J. Hu, H. Tang, X. Lin et al., "Doped titanium dioxide films prepared by pulsed laser deposition method," International Journal of Photoenergy, vol. 2012, Article ID 758539, 8 pages, 2012.

[36] J. Qian, G. Cui, M. Jing, Y. Wang, M. Zhang, and J. Yang, "Hydrothermal synthesis of nitrogen-doped titanium dioxide and evaluation of its visible light photocatalytic activity," International Journal of Photoenergy, vol. 2012, Article ID 198497, 6 pages, 2012.

[37] C.-C. Hu, T.-C. Hsu, and L.-H. Kao, "One-step cohydrothermal synthesis of nitrogen-doped titanium oxide nanotubes with enhanced visible light photocatalytic activity," International Journal of Photoenergy, vol. 2012, Article ID 391958, 9 pages, 2012. 
[38] A. V. Emeline, V. N. Kuznetsov, V. K. Rybchuk, and N. Serpone, "Visible-light-active titania Photocatalysts: the case of n-doped $\mathrm{TiO}_{2}$ s-properties and some fundamental issues," International Journal of Photoenergy, vol. 2008, Article ID 258394, 19 pages, 2008.

[39] J. A. Wang, R. Limas-Ballesteros, T. López et al., "Quantitative determination of titanium lattice defects and solid-state reaction mechanism in iron-doped $\mathrm{TiO}_{2}$ photocatalysts," Journal of Physical Chemistry, vol. 105, no. 40, pp. 9692-9698, 2001.

[40] J. C. Yu, J. G. Yu, and J. C. Zhao, "Enhanced photocatalytic activity of mesoporous and ordinary $\mathrm{TiO}_{2}$ thin films by sulfuric acid treatment," Applied Catalysis, vol. 36, no. 1, pp. 31-43, 2002.

[41] K. Kobayakawa, Y. Murakami, and Y. Sato, "Visible-light active $\mathrm{N}$-doped $\mathrm{TiO}_{2}$ prepared by heating of titanium hydroxide and urea," Journal of Photochemistry and Photobiology, vol. 170, no. 2, pp. 177-179, 2005.

[42] R. J. Tayade, P. K. Suroliya, R. G. Kulkarni, and R. V. Jasra, "Photocatalytic degradation of dyes and organic contaminants in water using nanocrystalline anatase and rutile $\mathrm{TiO}_{2}$," Science and Technology of Advanced Materials, vol. 8, no. 6, pp. 455-462, 2007.

[43] R. Asahi, T. Morikawa, T. Ohwaki, K. Aoki, and Y. Taga, "Visible-light photocatalysis in nitrogen-doped titanium oxides," Science, vol. 293, no. 5528, pp. 269-271, 2001.

[44] H. Irie, Y. Watanabe, and K. Hashimoto, "Nitrogenconcentration dependence on photocatalytic activity of $\mathrm{TiO}_{2-x} \mathrm{~N}_{x}$ powders," The Journal of Physical Chemistry, vol. 107, no. 23, pp. 5483-5486, 2003.

[45] O. Sacco, M. Stoller, V. Vaiano, A. Chianese, and D. Sannino, "On the comparison of different light sources in the photocatalytic degradation of tannery wastewater stream," in Proceedings of the 7th European Meeting on Solar Chemistry and Photocatalysis: Environmental Applications (SPEA '7), Oporto, Portugal, June 2012.

[46] S. De Gisi, M. Galasso, and G. De Feo, "Treatment of tannery wastewater through the combination of a conventional activated sludge process and reverse osmosis with a plane membrane," Desalination, vol. 249, no. 1, pp. 337-342, 2009.

[47] S. Sato, "Photo catalytic activity of $\mathrm{NO}_{x}$ doped $\mathrm{TiO}_{2}$ in the visible region," Chemical Physics Letters, vol. 123, no. 1-2, pp. 126-128, 1986.

[48] R. W. Matthews, "Photocatalytic oxidation and adsorption of methylene blue on thin films of near-ultraviolet-illuminated $\mathrm{TiO}_{2}$," Journal of the Chemical Society, vol. 85, no. 6, pp. 697707, 1989.

[49] P. Scherrer, "Bestimmung der Grösse und der inneren Struktur von Kolloidteilchen mittels Röntgenstrahlen," Nachr. Ges. Wiss. Göttingen, vol. 26, pp. 98-100, 1918.

[50] T. Ohsaka, F. Izumi, and Y. Fujiki,, "Raman spectrum of anatase, $\mathrm{TiO}_{2}$," Journal of Raman Spectroscopy, vol. 7, no. 6, pp. 321-324, 1978.

[51] S. P. S. Porto, P. A. Fleury, and T. C. Damen, "Raman spectra of $\mathrm{TiO}_{2}, \mathrm{MgF}_{2}, \mathrm{ZnF}_{2}, \mathrm{FeF}_{2}$, and $\mathrm{MnF}_{2}$," Physical Review, vol. 154, no. 2, pp. 522-526, 1967.

[52] Y. Djaoued, S. Badilescu, P. V. Ashrit, D. Bersani, P. P. Lottici, and R. Brüning, "Low temperature sol-gel preparation of nanocrystalline $\mathrm{TiO}_{2}$ thin films," Journal of Sol-Gel Science and Technology, vol. 24, no. 3, pp. 247-254, 2002.

[53] J. C. Parker and R. W Siegel, "Raman microprobe study of nanophase $\mathrm{TiO}_{2}$ and oxidation-induced spectral changes," Journal of Materials Research, vol. 5, no. 6, pp. 1246-1252, 1990.
[54] G. J. Exarhous and N. J. Hess, "Spectroscopic measurements of stress relaxation during thermally induced crystallization of amorphous titania films," Thin Solid Films, vol. 220, no. 1-2, pp. 254-260, 1992.

[55] D. Bersani, P. P. Lottici, and X. Z. Ding, "Phonon confinement effects in the Raman scattering by $\mathrm{TiO}_{2}$ nanocrystals," Applied Physics Letters, vol. 72, no. 1, pp. 73-75, 1998.

[56] M. Ivanda, S. Music, M. Gotic, A. Turkovic, A.M. Tonejc, and O. Gamulin, "The effects of crystal size on the Raman spectra of nanophase $\mathrm{TiO}_{2}$," Journal of Molecular Structure, vol. 480481, pp. 641-644, 1999.

[57] T. Mazza, E. Barborini, P. Piseri et al., "Raman spectroscopy characterization of $\mathrm{TiO}_{2}$ rutile nanocrystals," Physical Review, vol. 75, no. 4, Article ID 045416, 2007.

[58] S. Balaji, Y. Djaoued, and J. Robichaud, "Phonon confinement studies in nanocrystalline anatase- $\mathrm{TiO}_{2}$ thin films by micro Raman spectroscopy," Journal of Raman Spectroscopy, vol. 37, no. 12, pp. 1416-1422, 2006.

[59] K.R. Zhu, M.S. Zhang, Q. Chen, and Z. Yin, "Size and phononconfinement effects on low-frequency Raman mode of anatase $\mathrm{TiO}_{2}$ nanocrystal," Physics Letters, vol. 340, no. 1-4, pp. 220227, 2005.

[60] I. A. Alhomoudi and G. Newaz, "Residual stresses and Raman shift relation in anatase $\mathrm{TiO}_{2}$ thin film," Thin Solid Films, vol. 517, no. 15, pp. 4372-4378, 2009.

[61] C. R. Aita, "Raman scattering by thin film nanomosaic rutile $\mathrm{TiO}_{2}$," Applied Physics Letters, vol. 90, no. 21, pp. 213112213113, 2007.

[62] C. Yogi, K. Kojima, T. Takai, and N. Wada, "Photocatalytic degradation of methylene blue by Au-deposited $\mathrm{TiO}_{2}$ film under UV irradiation," Journal of Materials Science, vol. 44, no. 3, pp. 821-827, 2009.

[63] M. A. Rauf, M. A. Meetani, A. Khaleel, and A. Ahmed, "Photocatalytic degradation of Methylene Blue using a mixed catalyst and product analysis by LC/MS," Chemical Engineering Journal, vol. 157, no. 2-3, pp. 373-378, 2010. 


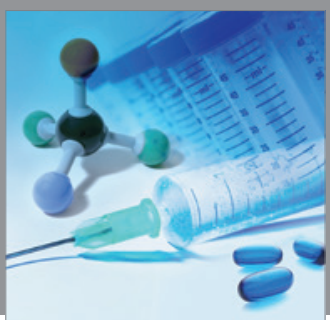

International Journal of

Medicinal Chemistry

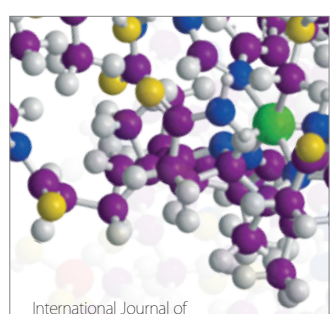

Carbohydrate Chemistry

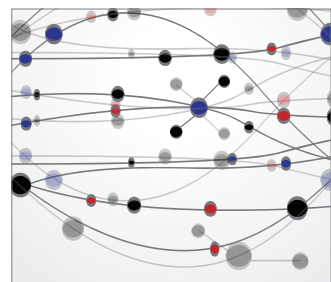

The Scientific World Journal
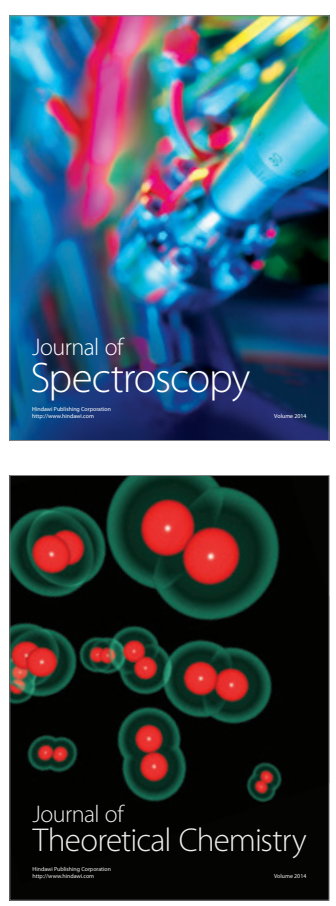
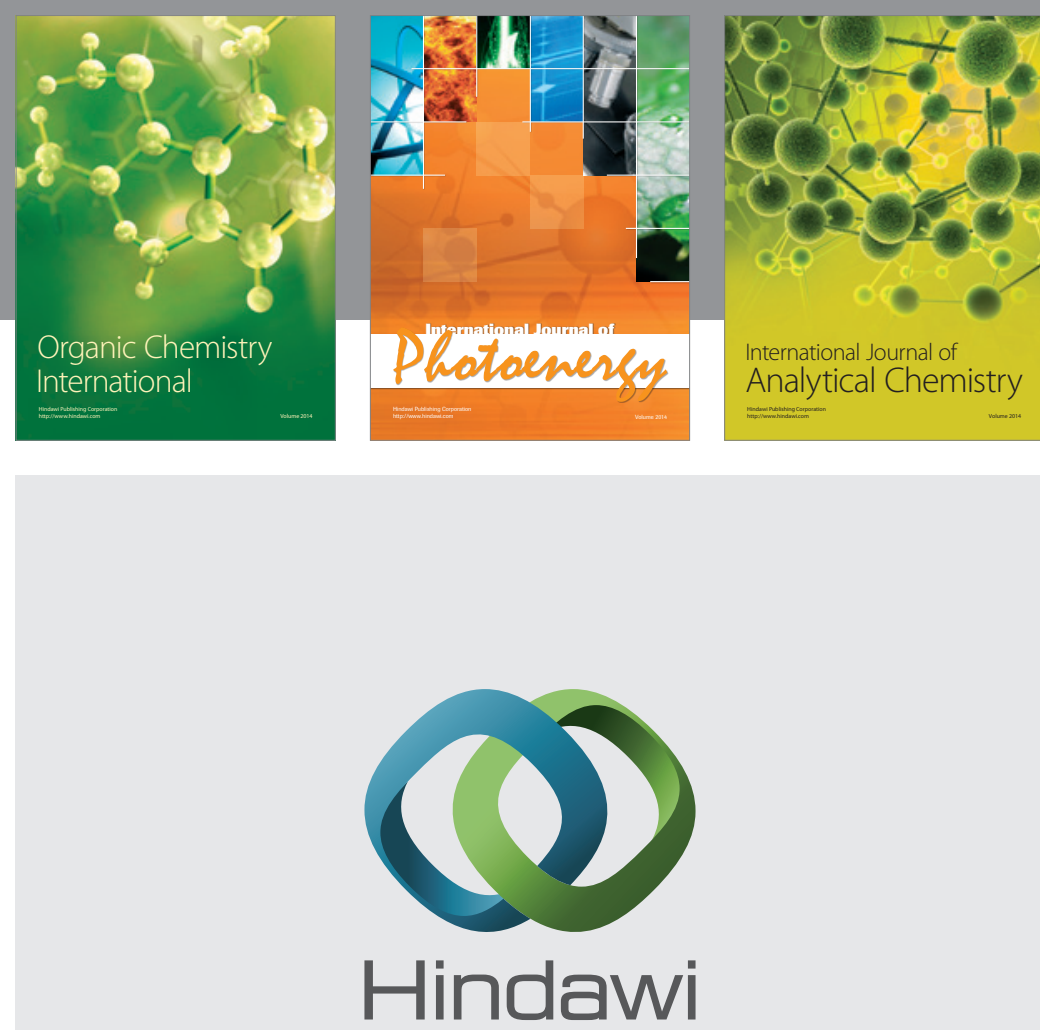

Submit your manuscripts at

http://www.hindawi.com
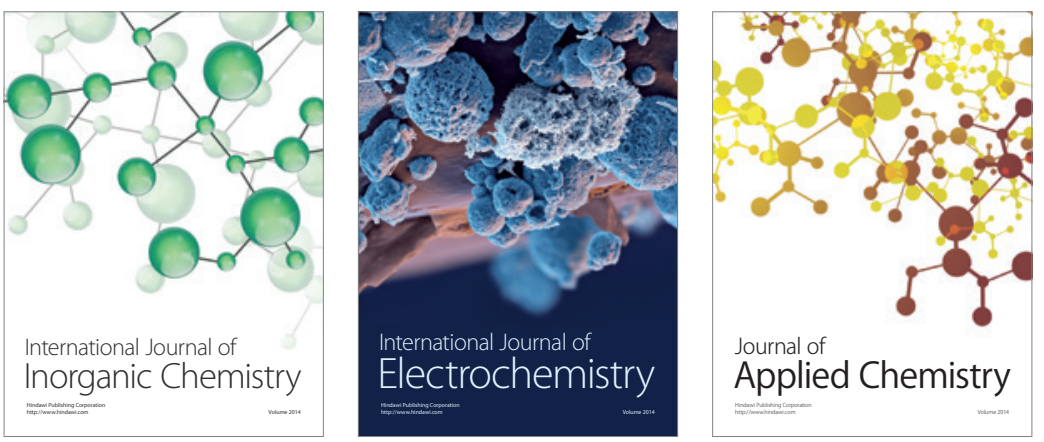

Journal of

Applied Chemistry
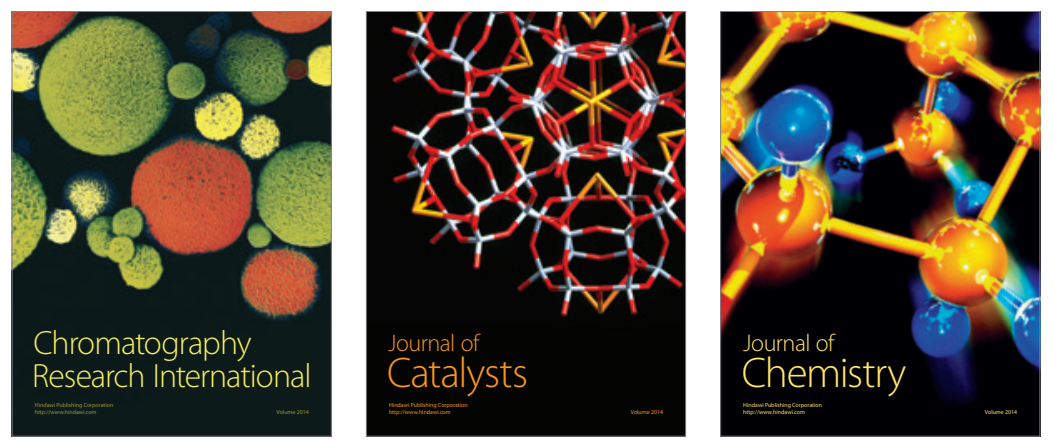
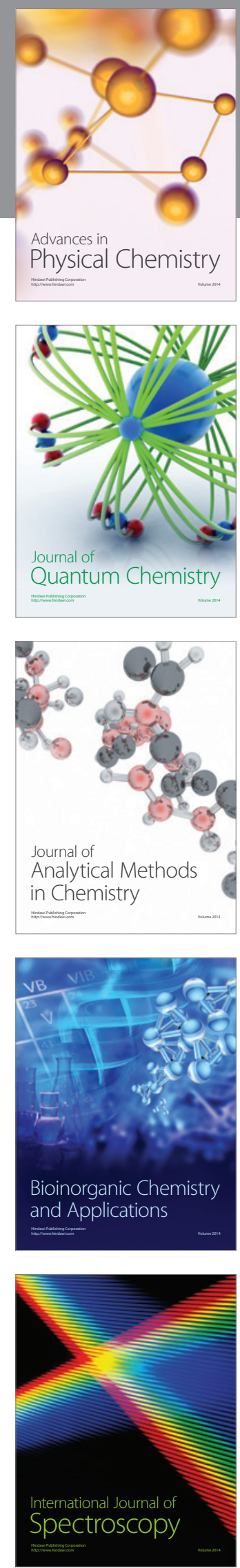